\title{
An Identification of Multiple Harmonic Sources in a Distribution System by Using Spectrogram
}

\author{
M. H. Jopri ${ }^{1}$, A. R. Abdullah ${ }^{2}$, M. Manap ${ }^{3}$, T. Sutikno ${ }^{4}$, M. R. Ab. Ghani ${ }^{5}$, \\ ${ }^{1,3}$ Center for Robotics and Industrial Automation (CeRIA), Faculty of Engineering Technology, Universiti Teknikal \\ Malaysia Melaka (UTeM), Malaysia \\ ${ }^{2,5}$ CeRIA, Faculty of Electrical Engineering, UTeM, Malaysia \\ ${ }^{4}$ Department of Electrical Engineering, Universitas Ahmad Dahlan (UAD), Yogyakarta, Indonesia
}

\begin{tabular}{|c|c|}
\hline Article Info & ABSTRACT \\
\hline Article history: & \multirow{10}{*}{$\begin{array}{l}\text { The identification of multiple harmonic sources (MHS) is vital to identify the } \\
\text { root causes and the mitigation technique for a harmonic disturbance. This } \\
\text { paper introduces an identification technique of MHS in a power distribution } \\
\text { system by using a time-frequency distribution (TFD) analysis known as a } \\
\text { spectrogram. The spectrogram has advantages in term of its accuracy, a less } \\
\text { complex algorithm, and use of low memory size compared to previous } \\
\text { methods such as probabilistic and harmonic power flow direction. The } \\
\text { identification of MHS is based on the significant relationship of spectral } \\
\text { impedances, which are the fundamental impedance }\left(\mathrm{Z}_{1}\right) \text { and harmonic } \\
\left.\text { impedance ( } \mathrm{Z}_{\mathrm{h}}\right) \text { that estimate the time-frequency representation (TFR). To } \\
\text { verify the performance of the proposed method, an IEEE test feeder with } \\
\text { several different harmonic producing loads is simulated. It is shown that the } \\
\text { suggested method is excellent with } 100 \% \text { correct identification of MHS. The } \\
\text { method is accurate, fast and cost-efficient in the identification of MHS in } \\
\text { power distribution arrangement. }\end{array}$} \\
\hline Received Feb 02, 2018 & \\
\hline Revised Apr 04, 2018 & \\
\hline Accepted Apr 18, 2018 & \\
\hline Keywords: & \\
\hline Harmonic source identification & \\
\hline Multiple harmonic sources & \\
\hline Spectral impedance & \\
\hline Spectrogram & \\
\hline Time-frequency distribution & \\
\hline
\end{tabular}

Copyright $\odot 2018$ Institute of Advanced Engineering and Science. All rights reserved.

\section{Corresponding Author:}

\author{
M. H. Jopri, \\ Center for Robotics and Industrial Automation (CeRIA), \\ Faculty of Engineering Technology, \\ Universiti Teknikal Malaysia Melaka (UTeM), Malaysia. \\ Email: hatta@utem.edu.my
}

\section{INTRODUCTION}

Nowadays in an advanced power distribution system, multiple harmonic sources (MHS) comprise nonlinear loads lead to the possible threat of a standard performance by the power system as per explained in [1]-[3]. Thus, it is vital to find the root cause, eliminate the harmonic pollution, and identify MHS through the best approach towards raising the power quality of the system [4], [5]. In addition, referring to the point of common coupling (PCC), MHS can be distinguished at the utility and client side which is known as upstream and downstream [6]-[8].

Various methodologies of MHS identification have been highlighted in the previous literature. However, there are no standards on the method to identify the dominant harmonic disturbances [30]. The earliest method to identify MHS is by using a power direction technique. However, this technique could not produce precise outcomes when the harmonics and phase angle were beyond $90^{\circ}$ [9-10]. Furthermore, a state estimation method is introduced with the execution of least square and Kirchhoff current law [11]. Nevertheless, a study [12] depicted that state estimation technique demands many measurement devices and a high setup cost for a large power system. Moreover, in the literature, the identification of MHS using the critical impedance method has also been discussed [13-16]. The crucial drawback of this technique is a prerequirement of source internal impedance values on the utility and client side. In practice, it is difficult to get those parameters without switching tests, which is costly [19-20]. To overcome the restriction of the critical 
impedance method, a harmonic current vector method is presented [21-23]. The measurement of client impedances can be performed without any switching testing. However, it needs long-term measurement and it is difficult to analyse harmonic impedances at the client side [10]. In earlier studies [24-25], the harmonic source estimation has been suggested by employing the harmonic state estimation (HSE) and Bayesian estimation. Unfortunately, this method requires a high multiplicity in the algorithmic and requires a high cost to set up the distributed measurement system station [26]. By using an alternative methodology that concentrates on two-point measurement strategy, impedances data can be obtained by comparing the data between the supply and incoming load utilizing frequency and phase approach [16-18]. This approach gives accurate impedance data, but then again, it is still high cost and difficult to practice [20]. In reality, accuracy, quick estimation and low cost are important elements to consider. However, limited studies have focused on these factors. Based on this discussion, the restriction of previous techniques can be overcome by employing time-frequency distribution (TFD).

This paper proposes a high accuracy, fast estimation and cost-efficient method to identify MHS utilizing a single-point measurement [8] at the PCC, utilizing a TFD which is spectrogram. The spectrogram is a suitable method that presents a signal in time and frequency representation which is known as timefrequency representation (TFR) [9], [16], [20], [30]. From these signals, spectral data can be monitored through changes of time. Furthermore, spectral information of the system can be extracted from TFR to identify the system characteristics and a common harmonic producing load which is an inverter will be used as a load in the system [3-4]. From the TFR, spectral impedances, which are fundamental impedance $Z_{l}$, and harmonic impedance $Z_{h}$, will be calculated accurately. Finally, utilizing the significant relationship between $Z_{l}$ and $Z_{h}$, the identification of MHS can be distinguished in a fast and accurate manner.

\section{METHODOLOGY}

A single point-measurement of voltage and current is implemented in this research, while spectrogram TFD is utilized for analyzing the signal parameters.

\subsection{Spectrogram}

The spectrogram is one of the techniques in TFD analysis and represents a dispersion of signal energy in time-frequency representation. It is a squared magnitude of STFT [31] thus an improvement of FFT to cater non-stationary signals [29]. By windowing the signal at first and then taking the Fourier transforms, the time-localization can be obtained correctly. Furthermore, this will lead to the rise of short time Fourier transform, (STFT) or windowed Fourier transform. Furthermore, the squared value of the STFT is usually used in the signal analysis, which is called a spectrogram and can be defined as in Equation 1 and Equation 2 [20].

$$
\begin{aligned}
& S_{v}(t, f)=\left|\int_{-\infty}^{\infty} v(\tau) w(\tau-t) e^{-j 2 \pi f} d t\right|^{2} \\
& S_{i}(t, f)=\left|\int_{-\infty}^{\infty} i(\tau) w(\tau-t) e^{-j 2 \pi f} d t\right|^{2}
\end{aligned}
$$

where $w(t)$ is observation windows. The Hanning window is selected with respect to IEC standards that characterize this window as suitable for analyzing harmonics [3] and is also chosen due to its lower peak side lope which has a narrow effect on other frequencies around fundamental value and other frequency components. The spectrogram is used in numerous applications and utilized as an initial investigative instrument as it has the property of non-producing cross-term parameters of TFD [5], [6].

\subsection{Implementation of Proposed Technique}

The implementation for MHS identification can be realized as demonstrated in Figure 1 and Figure

2. Referring to the PCC, there are four cases considered in this study as follows:

- No MHS within the distribution system.

- Downstream: When MHS located at customer side.

- Upstream: When MHS located at utility side.

- $\quad$ Both streams: When MHS located between utility and customer side.

First of all, the measurement data are analyzed using spectrogram and presented TFR. Furthermore, the parameters of the power system will be estimated from the power spectrum, and finally, the identification of harmonic sources is based on the significant relationship of spectral impedance, which is $\mathrm{Z} 1$ and $\mathrm{Zh}$ at the harmonic frequency. Meanwhile, to validate the proposed method, two different converter types, which are an AC-DC-AC PWM and a three-phase two-level single bridge converter with sinusoidal PWM modulation were used as a harmonic producing load (HPL) alternately in an IEEE 4-bus test feeder. 


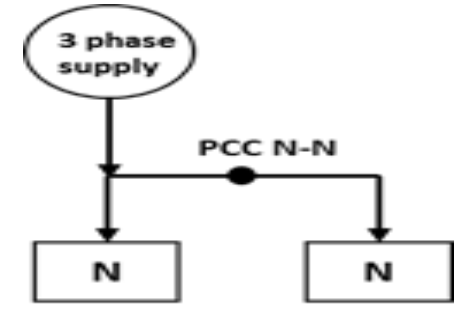

Figure 1. Case 1

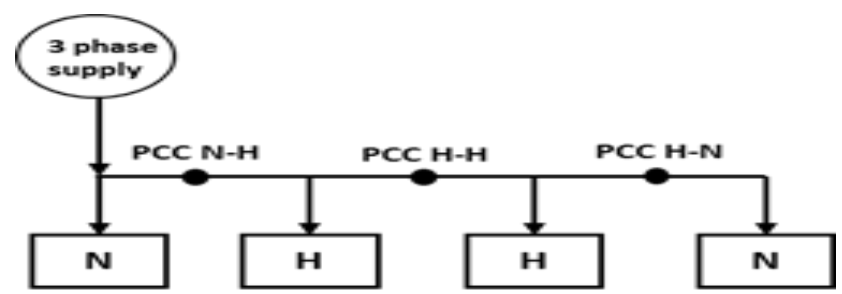

Figure 2. IEEE 4-bus test feeder for Case 2, 3 and 4

Whereby $\mathrm{N}$ is non-HPL and $\mathrm{H}$ is HPL

The implementation of the methodology in executing the proposed approach can be seen in Figure 3. From the proposed technique, it is demonstrated that the methodology can be effortlessly actualized in the system. This is due to the fact that there is no requirement for any complex calculation of signal parameters.

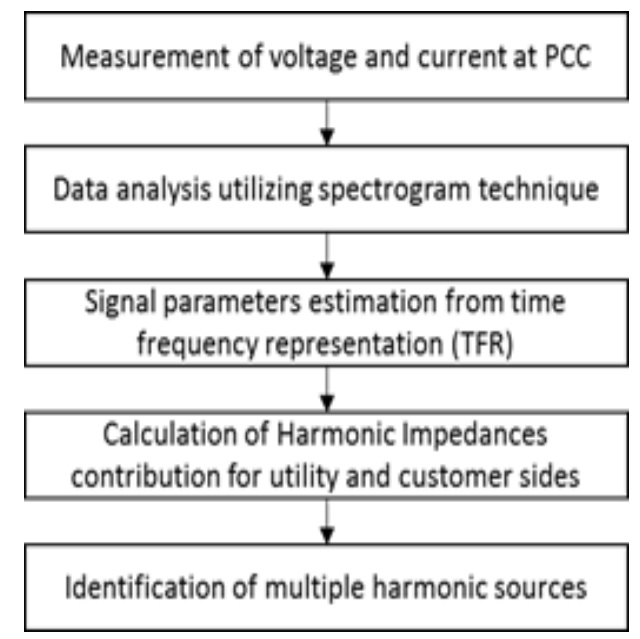

Figure 3. The implementation procedure in the identification of multiple harmonic sources at the PCC

\subsection{Signal Parameters}

Parameters of power quality signals are estimated from the TFR in order to provide the information of the signal in time. Meanwhile, the minimum width of the measurement window is ten cycles [27].

\subsubsection{Instantaneous RMS Voltage}

The RMS voltage, $V_{r m s}$, can also be derived from the TFR in time and referred to as instantaneous RMS voltage, $V_{r m s}(t)$ and written as [28],

$$
V_{r m s}(t)=\sqrt{\int_{0}^{f_{s}} P_{x}(t, f) d f}
$$

where $P x(t, f)$ is the TFR of the signal and fs is the sampling frequency of the system.

\subsubsection{Instantaneous RMS Fundamental Voltage}

Instantaneous RMS fundamental voltage, $V_{\text {lrms }}(t)$, is defined as the RMS voltage at power system frequency [28]. From the TFR, the $V_{1, r m s}(t)$, can be calculated as:

$$
\begin{aligned}
& V_{1 r m s}(t)=\sqrt{2 \int_{f_{l o}}^{f_{h i}} P_{x}(t, f) d f} \\
& f_{h i}=f_{0}+25 \mathrm{~Hz} \\
& f_{l o}=f_{0}-25 \mathrm{~Hz}
\end{aligned}
$$


Where $P_{x}(t, f)$ is the time-frequency representation of the signal and f0 is the fundamental frequency that corresponds to the power system frequency. $25 \mathrm{~Hz}$ is chosen for $f_{h i}$ and $f_{l o}$ since it can cover the fundamental frequency component to calculate the magnitude of the frequency component.

\subsubsection{Instantaneous Total Harmonic Distortion}

The instantaneous total harmonic distortion, $T H D(t)$, is used to measure how much harmonic content is in a waveform and expressed as [28],

$$
T H D(t)=\frac{\sqrt{\sum_{h=2}^{H} V_{h, r m s}(t)^{2}}}{V_{1 r m s}(t)}
$$

where $V_{h, r m s}(t)$ is RMS harmonic voltage from 2nd to 50th harmonic.

\subsubsection{Instantaneous Total Nonharmonic Distortion}

Besides harmonic, a signal also contains interharmonic components that are not multiple integers and can be quantified by using the instantaneous total nonharmonic distortion, $\operatorname{TnHD}(\mathrm{t})$, an index which is defined as [28],

$$
\operatorname{Tn} H D(t)=\frac{\sqrt{V_{r m s}(t)^{2}-\sum_{h=0}^{H} V_{h, r m s}(t)^{2}}}{V_{1 r m s}(t)}
$$

where $V_{h, r m s}(t)$ is RMS harmonic voltage from 2nd to 50th harmonic.

\subsubsection{Spectral Impedance}

The spectral impedance is defined as the ratio of the voltage phasor to the current phasor. Thus, it can be calculated using [12]:

$$
\begin{aligned}
& Z_{I}(t)=\frac{V_{1}(t) \angle \theta_{V 1}}{I_{1}(t) \angle \theta_{I 1}} \\
& Z_{h}(t)=\frac{V_{h}(t) \angle \theta_{V h}}{I_{h}(t) \angle \theta_{I h}}
\end{aligned}
$$

where, $h$ is a harmonic number at $3,5,7,9 \ldots \mathrm{n}$

\section{RESULTS AND DISCUSSION}

The accuracy and validity of this methodology are examined and verified in the distribution system with two different types of inverters. The significant relationship of spectral impedances in all cases will be observed due to distinguishing the location of MHS.

\subsection{Case 1: No Harmonic Sources within the System}

Figure 4(a) demonstrates the measured voltage and current in the time domain at PCC N-N. Meanwhile, Figure 4(b) shows that $T H D(t)$ and $\operatorname{Tn} H D(t)$ are zero percent. This result demonstrates that no harmonic and interharmonic components exist in the signal. Furthermore, TFRs in Figure 4(c) and 4(d) clearly show that only the fundamental component of voltage and current exist at $50 \mathrm{~Hz}$. From the TFR, the $Z_{l}$ is estimated with a value of $20 \mathrm{ohm}$ and presented in Figure 4(d).

Figure 4(e) clearly indicates the significant relationship between $Z_{l}$ and $Z_{h}$, that been estimated from TFR of spectral impedance for Case 1 can be concluded as:

$$
\begin{aligned}
& Z_{h}=0 \mathrm{ohm} \\
& Z_{l} \neq 0 \mathrm{ohm}
\end{aligned}
$$




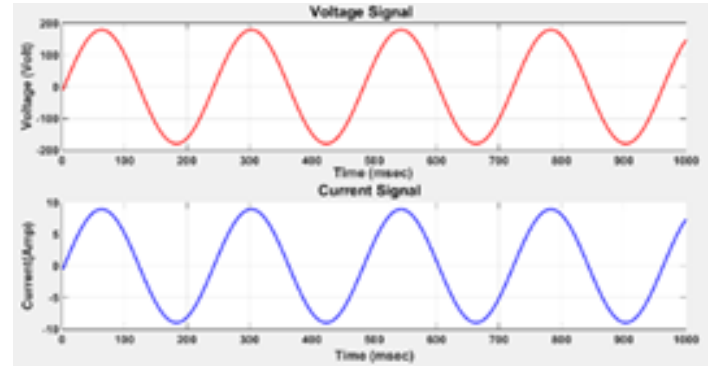

(a)

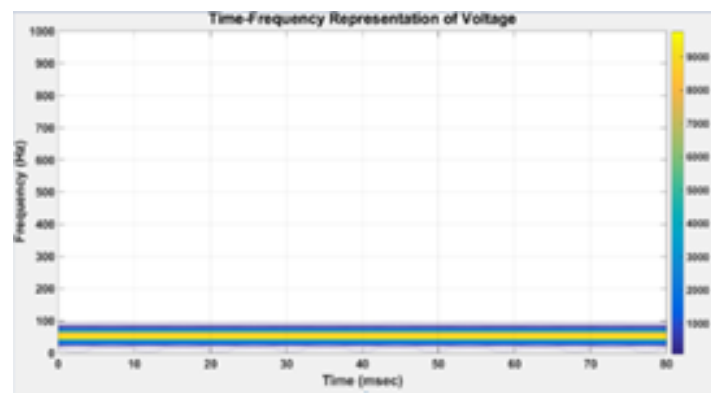

(c)

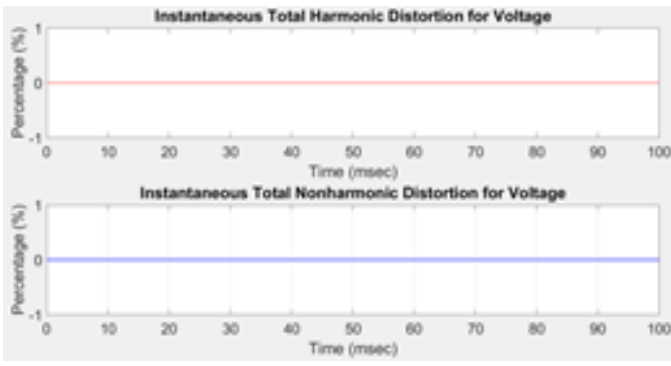

(b)

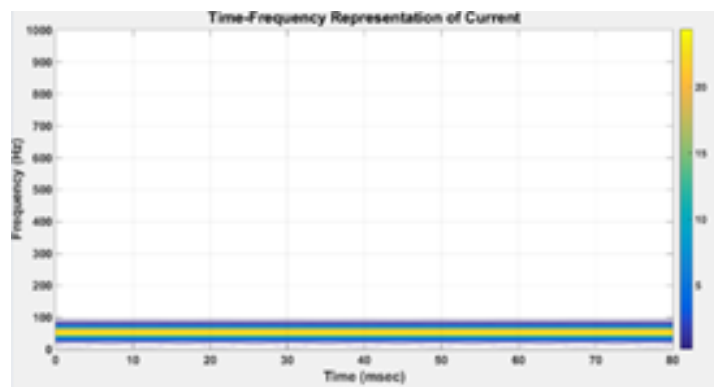

(d)

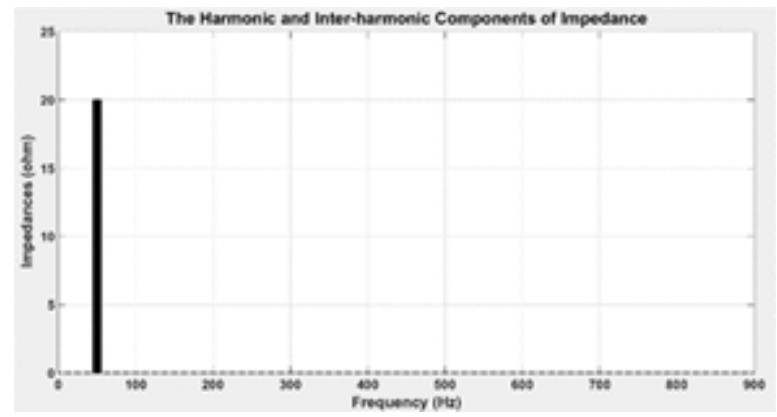

(e)

Figure 4. No harmonic sources. (a) Voltage and current signal, (b) $T H D(t)$ and $\operatorname{Tn} H D(t)$ for voltage, (c) TFR of voltage, (d) TFR of current, (e) Spectral impedance component

\subsection{Case 2: Harmonic Sources at Downstream}

In case 2, the effectiveness of the proposed method is analyzed when HPL is located at downstream and the measurement data are taken at the PCC N-H. Figure 5(a) shows the harmonic signal in the time domain when the AC-DC-AC PWM converter was used as HPL at downstream. Furthermore, Figure 5(b) illustrates that the $T H D(t)$ is in the range of $2.5 \%$ to $9.8 \%$ and it indicates that the signal contains the harmonic component. Meanwhile, the interharmonic index, which is $\operatorname{TnHD}(t)$ is in the range of $27 \%$ to $37 \%$. Figure 5(c) and 5(d) show the signals of five frequency components consist of the fundamental frequency $(50 \mathrm{~Hz})$, the harmonic component at $375 \mathrm{~Hz}$, and interharmonic components at $262.5 \mathrm{~Hz}, 587.5 \mathrm{~Hz}$ and $687.5 \mathrm{~Hz}$, respectively. Figure 5 (e) presents the TFR of spectral impedance and as depicted in Figure 5(f), the estimated impedance value of $Z_{l}$ is $8 \mathrm{ohm}$ and each $Z_{\mathrm{h}}$ has a value of $6 \mathrm{ohm}$. It is somewhat surprising that each value of $Z_{h}$ is smaller than $Z_{l}$ in this case. It is possible to hypothesize that there is a possible significant relationship between $Z_{l}$ and $Z_{h}$ in identifying the location of the harmonic source. Therefore, to conclude the findings in this case, further analysis was conducted by replacing the HPL with a three-phase two-level single bridge converter. 


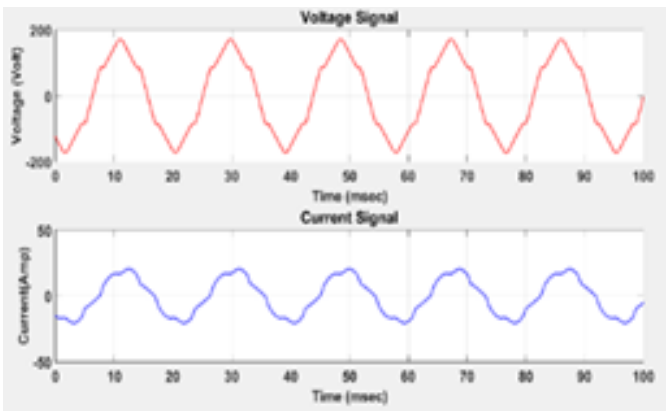

(a)

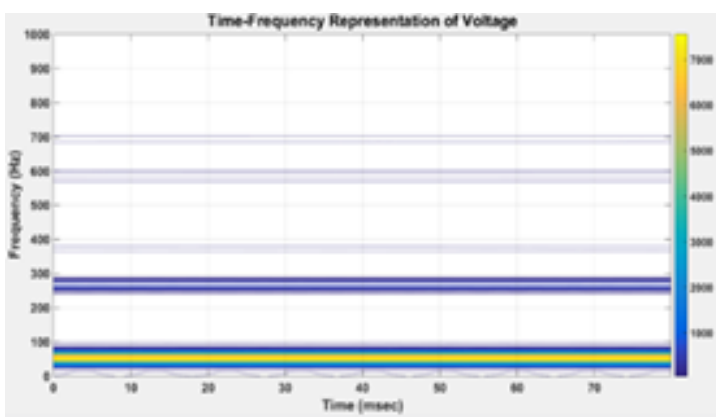

(c)

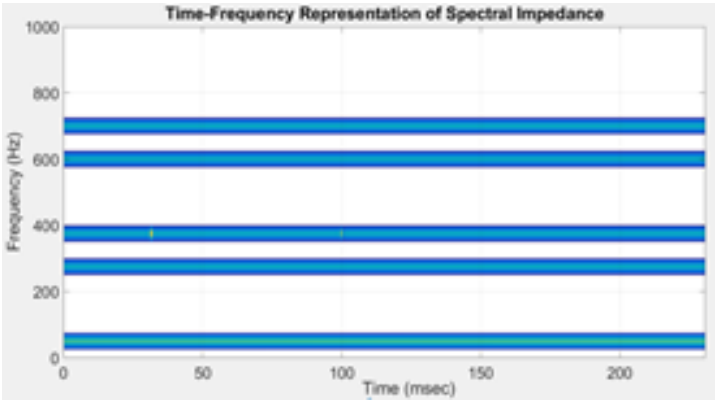

(e)

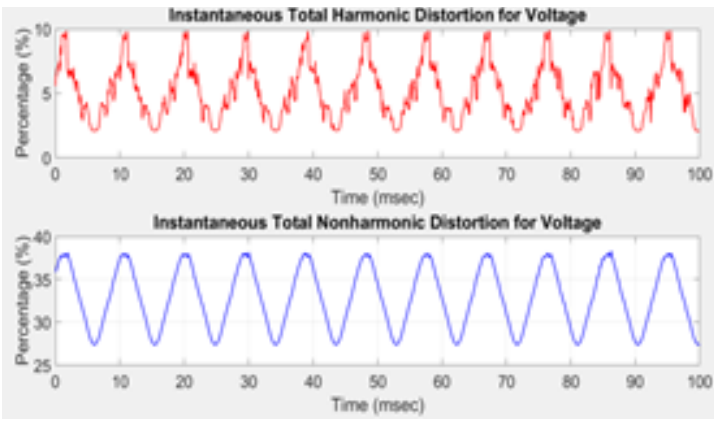

(b)

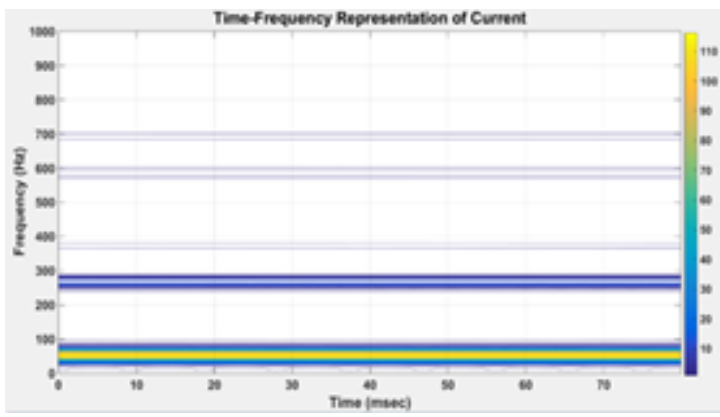

(d)

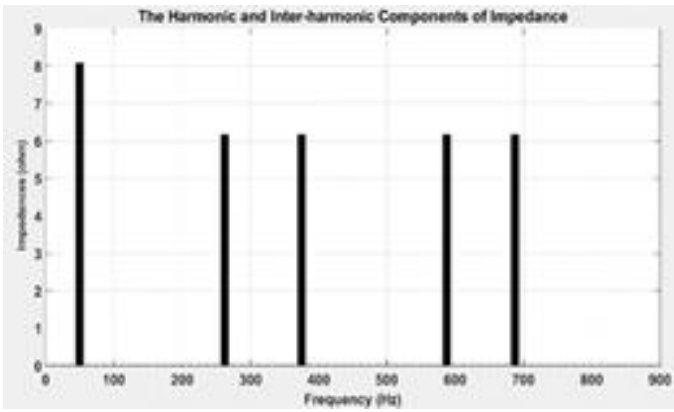

(f)

Figure 5. AC-DC-AC PWM converter as a harmonic source at upstream. (a) Voltage and current signal,

(b) $T H D(t)$ and $\operatorname{Tn} H D(t)$ for voltage (c) TFR of voltage, (d) TFR of current, (e) TFR of spectral impedance, (f) Spectral impedance component

The voltage and current signal as shown in Figure 6 (a) is obtained when a three-phase two-level single bridge converter is used as HPL at downstream. Furthermore, 6(b) illustrates that the $T H D(t)$ is in the range of $2 \%$ to $8 \%$ and it shows that the signal comprises a harmonic component. Meanwhile, the $\operatorname{Tn} H D(t)$ is in the range of $27 \%$ to $38 \%$. In addition, Figure 6(c) and 6(d) depict the TFR of voltage and current. It can be seen from the figures that the fundamental component has $50 \mathrm{~Hz}$, harmonic components at $375 \mathrm{~Hz}$ and interharmonic components discovered at $262.5 \mathrm{~Hz}$ and $587.5 \mathrm{~Hz}$, respectively. Furthermore, Figure 6(e) presents the TFR of spectral impedance. Figure 6(f) shows the estimated value of $Z_{l}$ is $11 \mathrm{ohm}$, while each $Z_{\mathrm{h}}$ has a value of $8.5 \mathrm{ohm}$. What is surprising is that each value of $Z_{h}$ is smaller than $Z_{l}$ which is similar to the previous result. The outcomes of this study have proven the significant relationship of spectral impedance in identifying the MHS. 


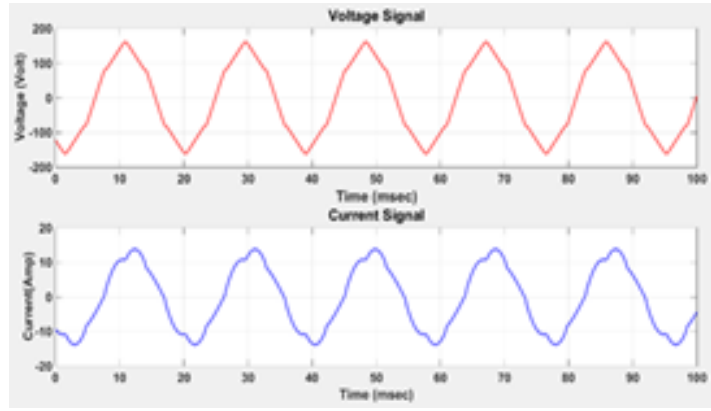

(a)

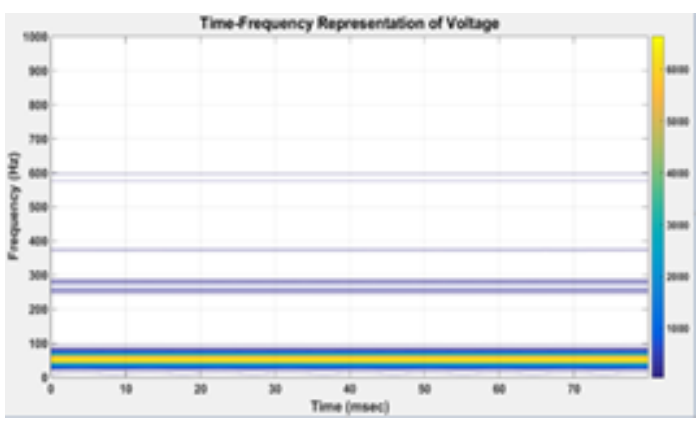

(c)

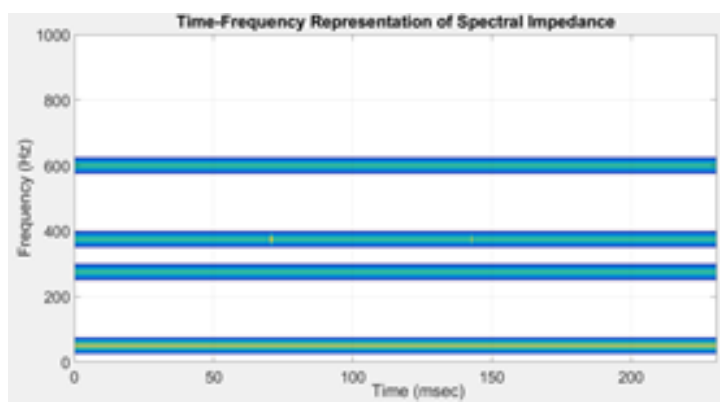

(e)

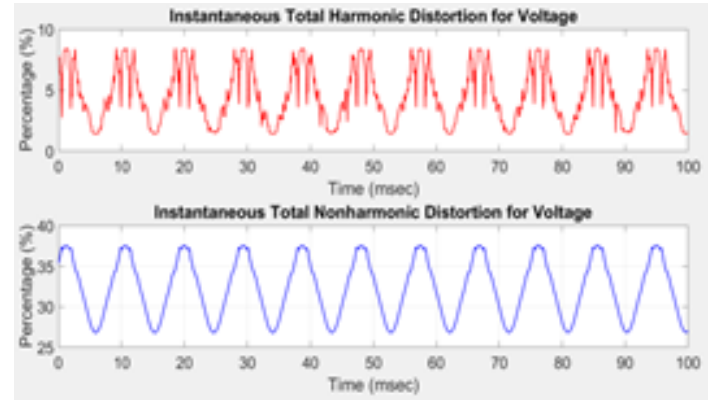

(b)

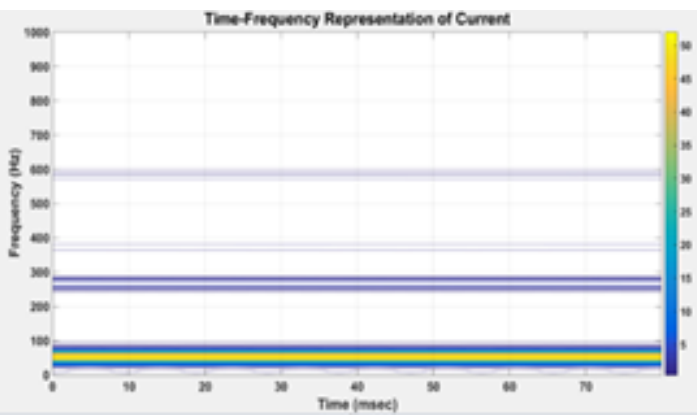

(d)

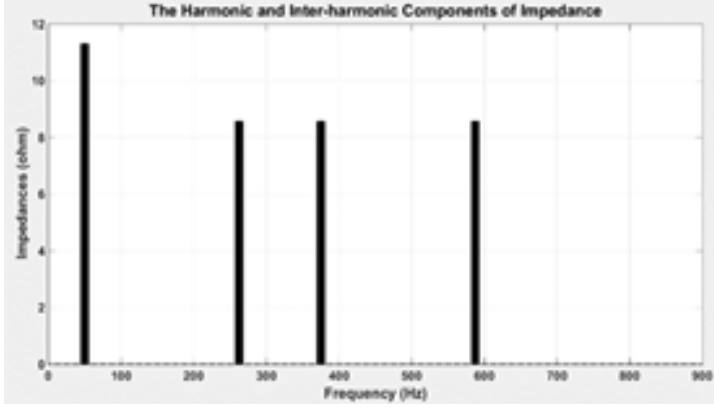

(f)

Figure. 6. Three-phase two-level single bridge converter as a harmonic source at upstream. (a) Voltage and current signal, (b) $T H D(t)$ and $T n H D(t)$ for voltage, (c) TFR of voltage, (d) TFR of current, (e) TFR of spectral impedance, (f) Spectral impedance component

The results obtained from Figure 5(f) and Figure 6(f) of Case 2 clearly indicates that $Z_{l}$ value is always greater than $Z_{h}$. Therefore, the significant relationship of spectral impedance for Case 2 can be concluded as:

$$
Z_{l}>Z_{h}
$$

\subsection{Case 3: Harmonic Sources at Upstream and Downstream}

The goal of this case study is to localize the harmonic sources when both streams contain the HPL and the measurement is taken at PCC H-H. It is hypothesized that another significant relationship of spectral impedance will be identified from this case. Current and voltage signals of this case are shown in Figure 7(a) when an AC-DC-AC PWM converter acted as HPL at upstream and downstream. As can be seen from Figure $7(\mathrm{~b})$, the $T H D(t)$ is in the range of $3 \%$ to $10 \%$ and it indicates that the signal contains the harmonic component. Meanwhile, the interharmonic index which is $\operatorname{Tn} H D(t)$ is in the range of $27 \%$ to $37.5 \%$. Figure 7 (c) and 7(d) show the signals of five frequency components consist of the fundamental frequency $(50 \mathrm{~Hz})$, the harmonic component at $375 \mathrm{~Hz}$, and interharmonic components at $262.5 \mathrm{~Hz}, 587.5 \mathrm{~Hz}$ and $687.5 \mathrm{~Hz}$, respectively. In addition, Figure 7(e) presents the TFR of spectral impedance. As shown in Figure 7(f), the 
estimated spectral impedance from TFR comprise of $Z_{l}$ is $13 \mathrm{ohm}$, while each $Z_{h}$ has a value of $14.5 \mathrm{ohm}$. Interestingly, is it observed that each value of $Z_{h}$ is greater than $Z_{l}$ when the MHS are located at downstream and upstream. To strengthen the preliminary findings, the MHS was replaced with a three-phase two-level single bridge converter and properly analyzed in the next discussion.

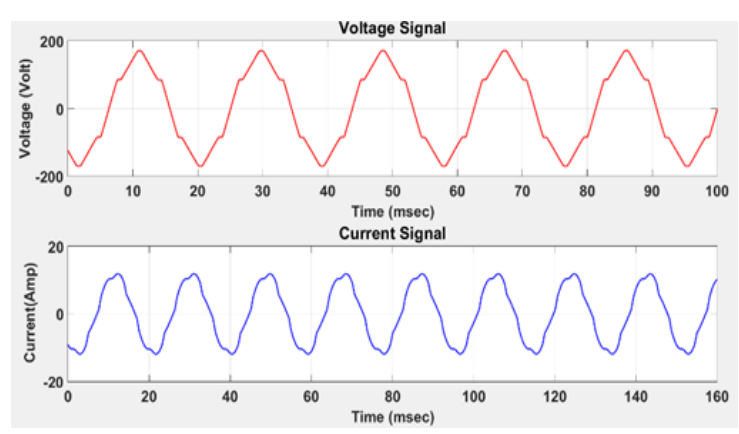

(a)

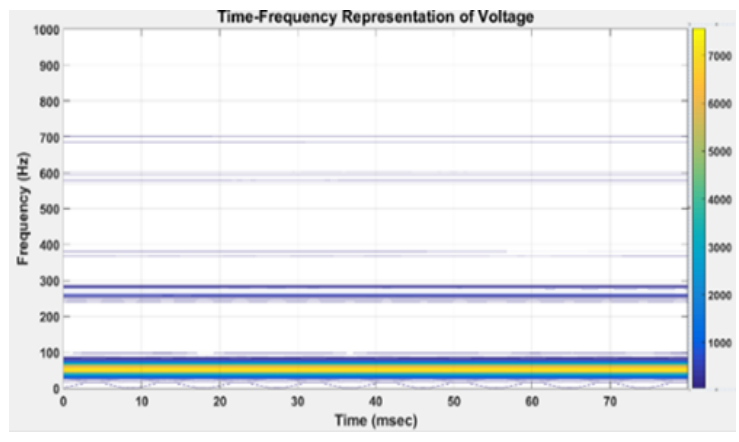

(c)

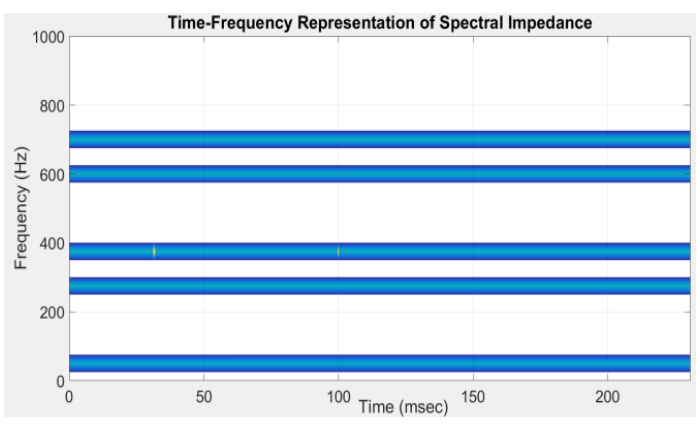

(e)

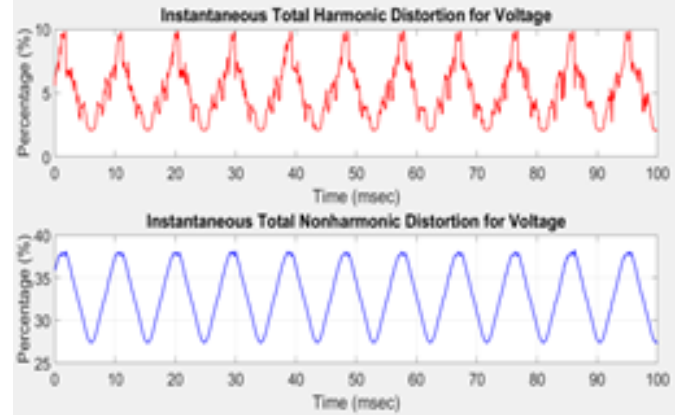

(b)

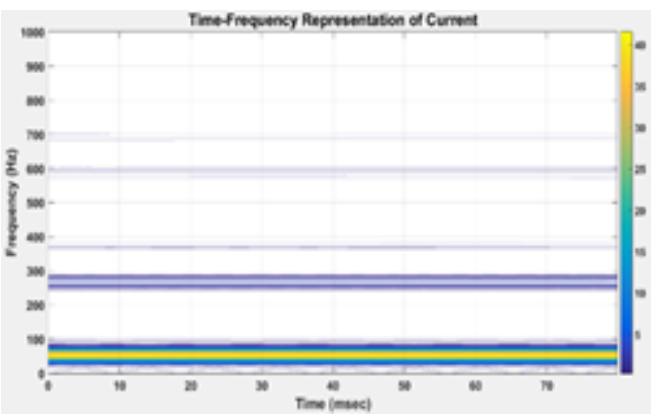

(d)

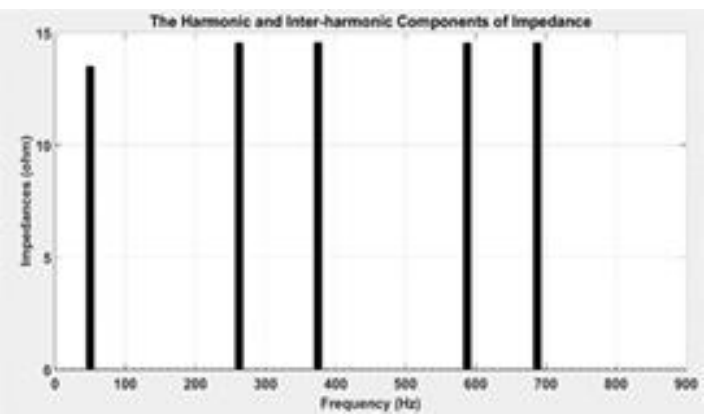

(f)

Figure 7. AC-DC-AC PWM converter as a harmonic source at upstream and downstream. (a) Voltage and current signal, (b) $T H D(t)$ and $T n H D(t)$ for voltage, (c) TFR of voltage, (d) TFR of current, (e) TFR of spectral impedance, (f) Spectral impedance component

For further investigation of Case 3, the three-phase two-level single bridge converter is employed as HPL at upstream and downstream. Figure 8(a) shows the signal of voltage and current in the time domain at PCC H-H. Moreover, Figure $8(\mathrm{~b})$ shows that the $T H D(t)$ is in the range of $2.5 \%$ to $8 \%$ and it indicates that the signal contains the harmonic component. Meanwhile, the interharmonic index, shown as $\operatorname{Tn} H D(t)$ is in the range of $27 \%$ to $37 \%$. Figure $8(\mathrm{c})$ and $8(\mathrm{~d})$ show the signals comprise a fundamental frequency at $50 \mathrm{~Hz}$, the harmonic component at $375 \mathrm{~Hz}$, and interharmonic components at $262.5 \mathrm{~Hz}$ and $587.5 \mathrm{~Hz}$, respectively. Besides, Figure 8(e) depicts the TFR of the spectral impedance, and it is apparent from Figure 8(f) that the $Z_{l}$ is estimated with a value of $18 \mathrm{ohm}$ and each $Z_{h}$ has a value of $22 \mathrm{ohm}$. Interestingly, the spectral impedance relationship, in this case, is similar even when using a different type of converter such as the HPL, whereby 
each of $Z_{h}$ is greater than the $Z_{l}$. It is interesting to observe that in this case, the significant spectral impedance relationship can be obtained from the proposed method and utilized in identifying the MHS.

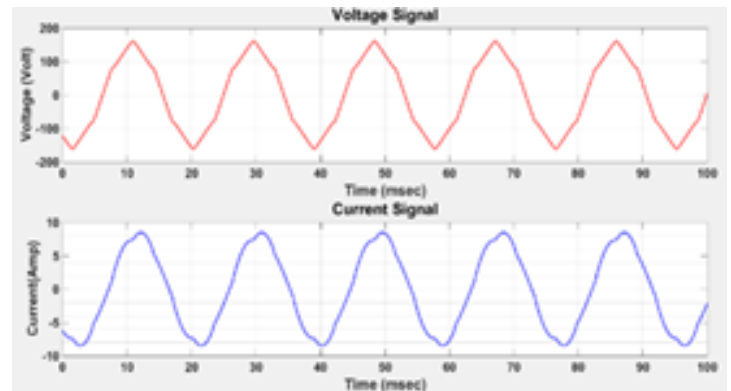

(a)

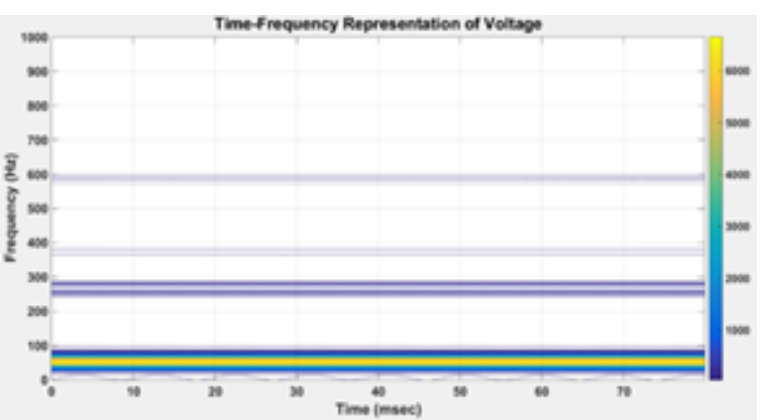

(c)

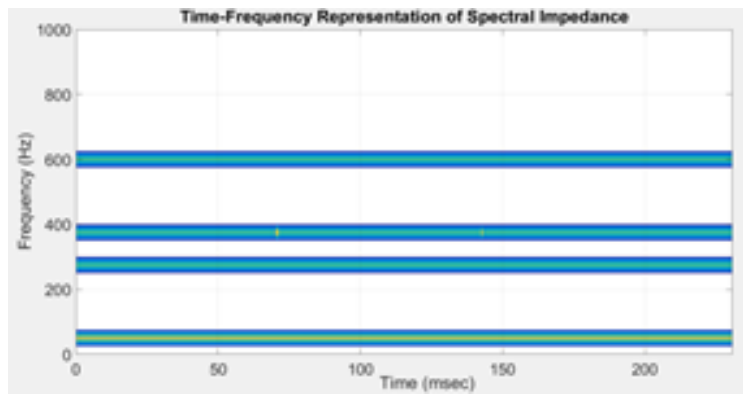

(e)

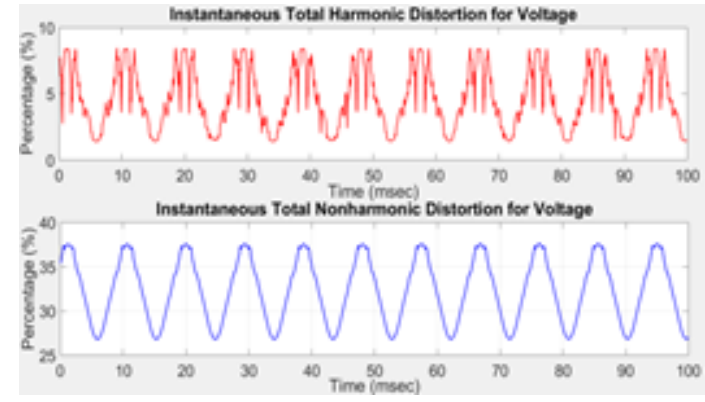

(b)

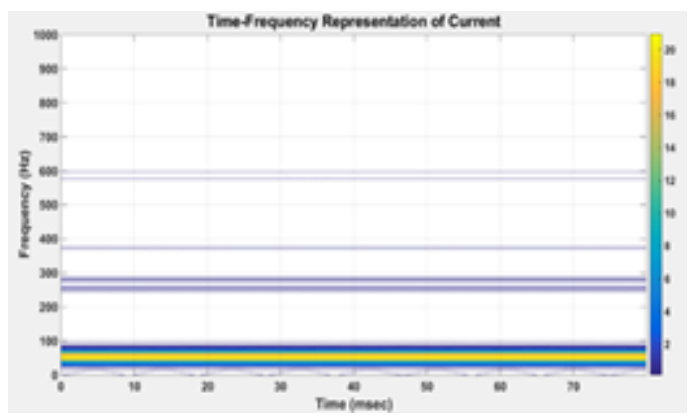

(d)

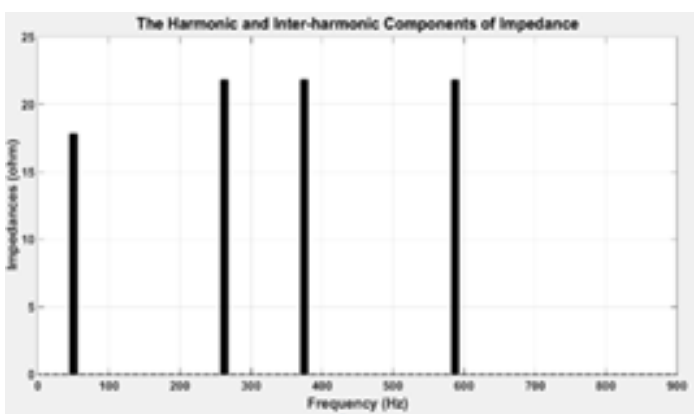

(f)

Figure 8. Three-phase two-level single bridge converter as a harmonic source at upstream and downstream. (a) Voltage and current signal, (b) $T H D(t)$ and $\operatorname{Tn} H D(t)$ for voltage, (c) TFR of voltage, (d) TFR of current, (e) TFR of spectral impedance, (f) Spectral impedance component

The evidence from Figure 7(f) and Figure 8(f) clearly indicate that the Z1 is always smaller than the $\mathrm{Zh}$ when the MHS is located at downstream and upstream. Thus, the significant relationship of spectral impedances for Case 4 can be written as:

$$
Z_{l}<Z_{h}
$$

\subsection{Case 4: Harmonic Sources at Upstream}

With the aim of identifying the HPL located upstream, Case 4 is executed with an AC-DC-AC PWM converter as HPL downstream, and a measurement is taken at PCC H-N. Figure 9(a) shows the voltage and current signal in time domain. As illustrated in Figure $9(\mathrm{~b})$, the $\mathrm{THD}(\mathrm{t})$ is in the range of $2.5 \%$ to $10 \%$, indicating that the signal contains the harmonic component. Meanwhile, the range of TnHD (t) is between $28 \%$ to $38 \%$. In addition, Figure $9(\mathrm{c})$ and $9(\mathrm{~d})$ show the components of the signal that consist of the 
fundamental frequency $(50 \mathrm{~Hz})$, the harmonic component at $375 \mathrm{~Hz}$, and interharmonic components at $262.5 \mathrm{~Hz}, 587.5 \mathrm{~Hz}$ and $687.5 \mathrm{~Hz}$, respectively. Figure $9(\mathrm{e})$ also presents the TFR of spectral impedance and Figure 9(f) shows that the estimated value of $\mathrm{Z} 1$ and $\mathrm{Zh}$ are equal with a value of $40 \mathrm{ohm}$. It is, therefore, likely that there is a relationship of spectral impedance in this case. To verify this hypothesis, the HPL was replaced with a three-phase two-level single bridge converter.

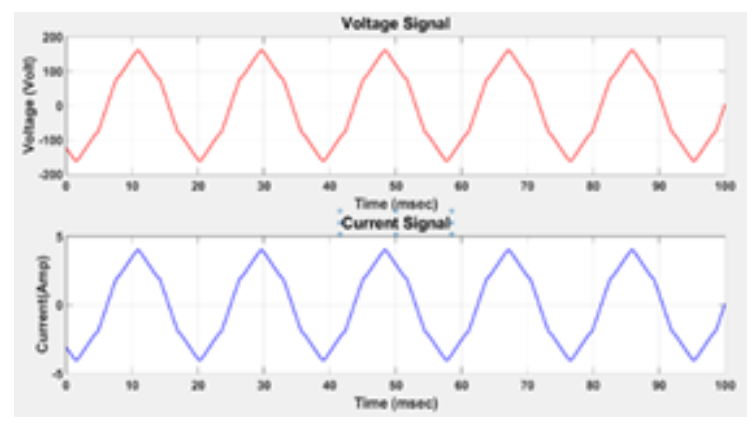

(a)

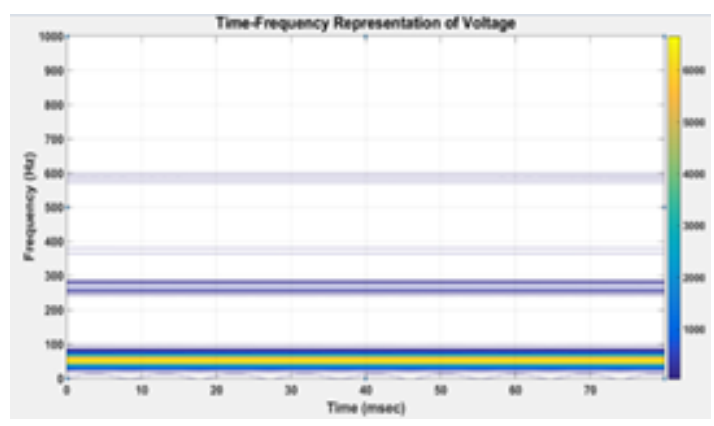

(c)

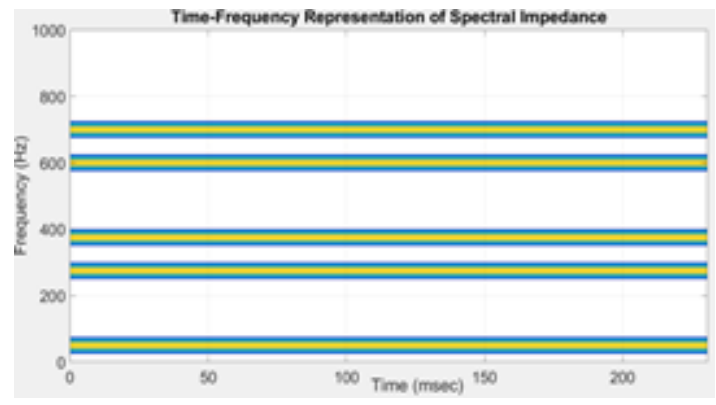

(e)

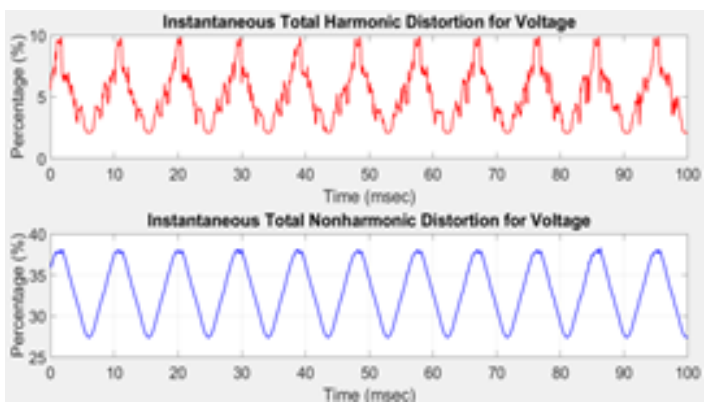

(b)

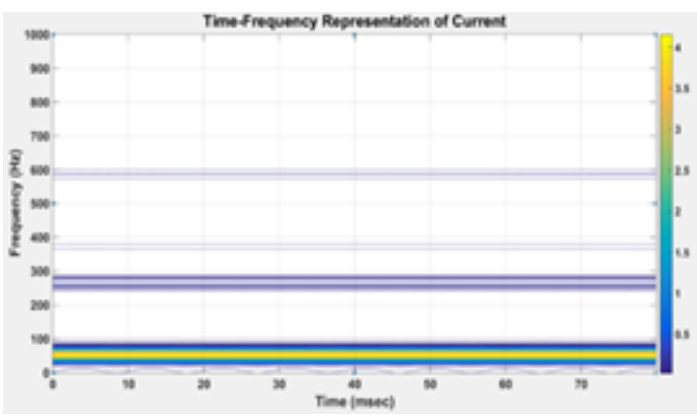

(d)

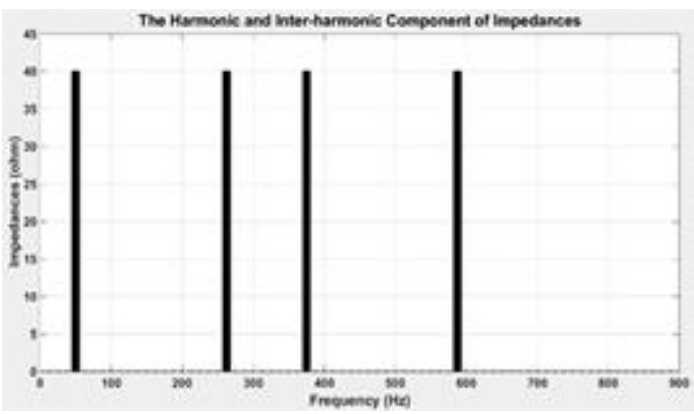

(f)

Figure 9. AC-DC-AC PWM converter as a harmonic source at downstream. (a) Voltage and current signal,

(b) $\operatorname{THD}(\mathrm{t})$ and $\operatorname{TnHD}(\mathrm{t})$ for voltage, (c) TFR of voltage, (d) TFR of current, (e) TFR of spectral impedance, (f) Spectral impedance component

A three-phase two-level single bridge converter replaces the previous MHS and the time domain signals are as shown in Figure 10(a). In the meantime, Figure 10(b) shows that the THD(t) is in the range of $2.5 \%$ to $10 \%$ and the $\operatorname{TnHD}(t)$ is between $27 \%$ to $37 \%$. Figure $10(\mathrm{c})$ and $10(\mathrm{~d})$ show the signals consist of a fundamental frequency of $50 \mathrm{~Hz}$, the harmonic component at $375 \mathrm{~Hz}$, and interharmonic components at $262.5 \mathrm{~Hz}$ and $587.5 \mathrm{~Hz}$, respectively. Figure $10(\mathrm{e})$ also depicts the TFR of the spectral impedance. As can be observed in Figure 10(f), the $Z_{l}$ and $Z_{h}$ were estimated at $40 \mathrm{ohm}$. The results indicate that the value of the $Z_{l}$ and $Z_{h}$ are constantly equal in this case. 


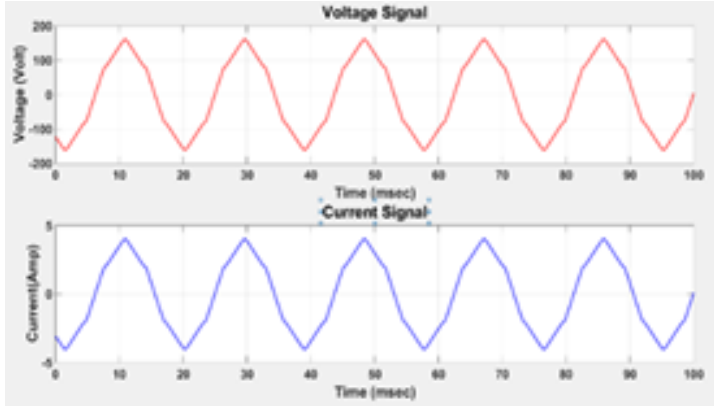

(a)

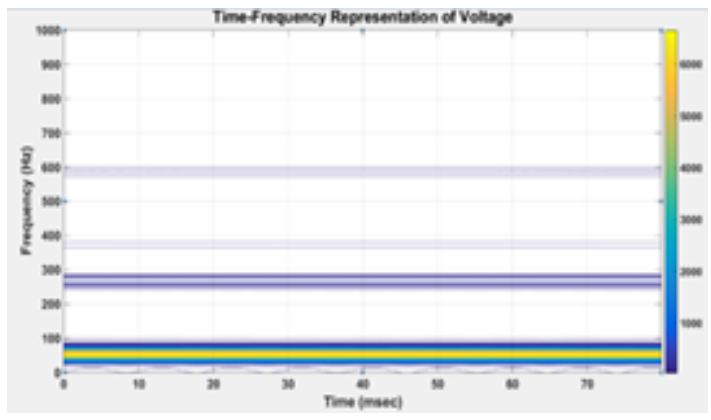

(c)

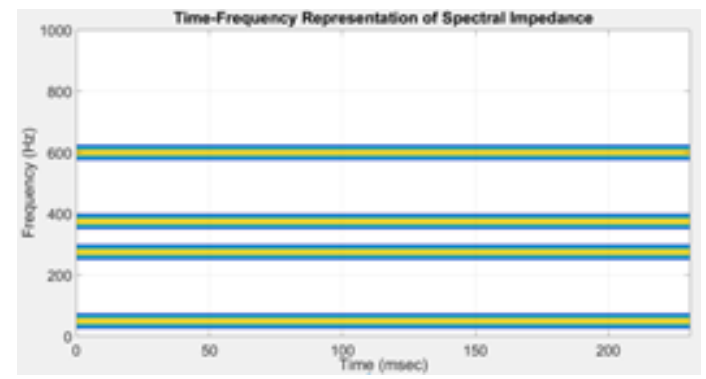

(e)

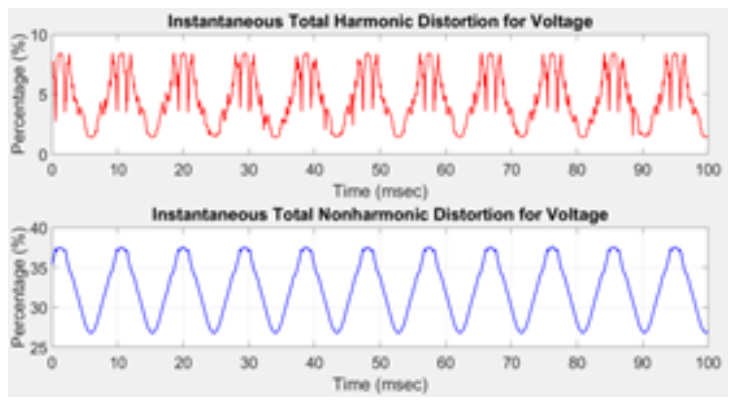

(b)

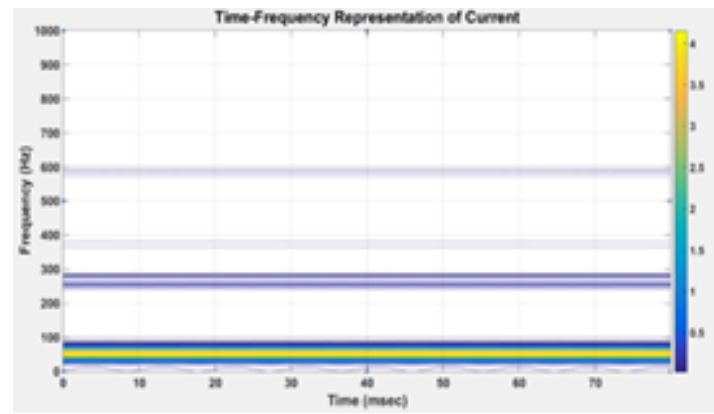

(d)

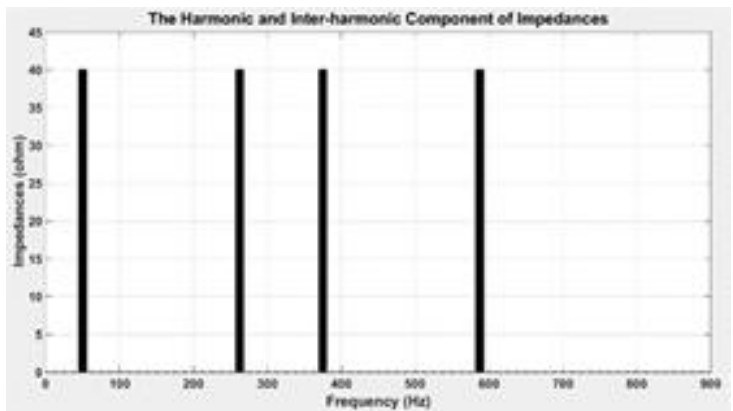

(f)

Figure 10. Three-phase two-level single bridge converter as a harmonic source at downstream. (a) Voltage and current signal, (b) THD(t) and TnHD(t) for voltage, (c) TFR of voltage, (d) TFR of current, (e) TFR of spectral impedance, (f) Spectral impedance component

It is apparent from Figure 9(f) and Figure 10(f), that the value of the $Z_{l}$ and $Z_{h}$ are constantly similar for Case 4. Therefore, the significant relationship of spectral impedances for Case 4 can be concluded as:

$Z_{l}=Z_{h}$

Table 1. The Significant Relationship of Spectral Impedance for MHS Localisation

\begin{tabular}{cccc}
\hline Case & Upstream & Downstream & Spectral Impedance $(\Omega)$ \\
\hline 1 & $\mathrm{~N}$ & $\mathrm{~N}$ & $Z_{h}=0$ \\
2 & $\mathrm{~N}$ & $\mathrm{H}$ & $Z_{l} \neq 0$ \\
3 & $\mathrm{H}$ & $\mathrm{H}$ & $Z_{l}>Z_{h}$ \\
4 & $\mathrm{H}$ & $\mathrm{N}$ & $Z_{l}<Z_{h}$ \\
\hline
\end{tabular}

Where by $\mathrm{N}$ is non-HPL, $\mathrm{H}$ is HPL, the $Z_{l}$ is fundamental impedance and $Z_{h}$ is harmonic impedance. 


\section{CONCLUSION}

The current findings in this study indicate the significant relationship and noteworthy contributions of spectral impedance in MHS identification. The previous methods such as power direction method and probabilistic method that require a high cost to set up a multi-point measurement station with high multiplicity use of the algorithm. However, the proposed method only requires a single point-measurement that utilizes a fast and simple algorithm that is short time Fourier transform-based.

The validation of the proposed method is done by using two different types of MHS. Based on Table 1, MHS in the power system can be identified and distinguished clearly in a significant pattern as follows:

- If the $Z_{h}$ is 0 ohm, there is no MHS within the system.

- If the $Z_{l}$ is greater than $Z_{h}$, there is MHS at downstream.

- If the $Z_{l}$ is smaller than $Z_{h}$, there are MHS at upstream and downstream.

- If the $Z_{l}$ is equal to $Z_{h}$, there is MHS at upstream.

Thus, the improved methodology proposed can be used accurately and quickly to obtain the significant relationship of spectral impedances in order to distinguish the location of MHS. In addition, the proposed method is excellent and provides $100 \%$ correct identification of MHS in the power system.

\section{ACKNOWLEDGMENT}

This research is supported by Advanced Digital Signal Processing Laboratory (ADSP Lab). Special thanks also to the Faculty of Electrical Engineering and Engineering Technology of Universiti Teknikal Malaysia Melaka (UTeM), Center for Robotics and Industrial Automation (CeRIA) of UTeM, Ministry of Higher Education Malaysia (MOHE) and Ministry of Science, Technology and Innovation (MOSTI) for giving their cooperation and funding for this research with grant number 06-01-14-SF00119 L00025. Their support is gratefully acknowledged.

\section{REFERENCES}

[1] Yunus AR, Abu F, Jabar J, Ahmad A. Empowering Smart Customer to Participate in Electricity Supply System. Australian Journal of Basic and Applied Science. 2015;9(4):110-4.

[2] D'Antona G, Muscas C, Sulis S. Localization of nonlinear loads in electric systems through harmonic source estimation. IEEE Transactions on Instrumentation and Measurement. 2011 Oct;60(10):3423-30.

[3] Farhoodnea M, Mohamed A, Shareef H. A single point measurement method for evaluating harmonic contributions of utility and customer in power distribution systems. Journal of Applied Sciences. 2011 Feb;11(2):257-65.

[4] Yin Z, Sun Y, Yu T. New methods exploration for harmonic source identification technologies. InElectric Utility Deregulation and Restructuring and Power Technologies (DRPT), 2011 4th International Conference on 2011 Jul 6 (pp. 399-402). IEEE.

[5] Sutikno T, Manap M, Yusoff MR. A Utilisation of Improved Gabor Transform for Harmonic Signals Detection and Classification Analysis. International Journal of Electrical and Computer Engineering (IJECE). 2017 Feb 1;7(1):218.

[6] Farhoodnea M, Mohamed A, Shareef H, Zayandehroodi H. An enhanced method for contribution assessment of utility and customer harmonic distortions in radial and weakly meshed distribution systems. International Journal of Electrical Power \& Energy Systems. 2012 Dec 1;43(1):222-9.

[7] Banshwar A, Chandel AK. Identification of harmonic sources using fuzzy logic. InPower Electronics, Drives and Energy Systems (PEDES) \& 2010 Power India, 2010 Joint International Conference on 2010 Dec 20 (pp. 1-7). IEEE.

[8] Liu Y, Gong H, Xiao XY, Yang H. Harmonic source location at the point of common coupling based on the nonlinearity index of load. InPower and Energy Engineering Conference, 2009. APPEEC 2009. Asia-Pacific 2009 Mar 27 (pp. 1-5). IEEE.

[9] Yusoff MR, Sutikno T. A Fast Localization of Multiple Harmonic Sources for Rectifier Loads by Utilizing Periodogram. Telkomnika. 2017 Mar 1;15(1).

[10] Moradloo M, Tabrizi MA, Karshenas HR. A new method for identification of main harmonic source based on the superposition and critical impedance methods. InPower Symposium, 2008. NAPS'08. 40th North American 2008 Sep 28 (pp. 1-6). IEEE.

[11] Saxena D, Bhaumik S, Singh SN. Identification of multiple harmonic sources in power system using optimally placed voltage measurement devices. IEEE Transactions on Industrial Electronics. 2014 May;61(5):2483-92.

[12] D'Antona G, Muscas C, Sulis S. State estimation for the localization of harmonic sources in electric distribution systems. IEEE Transactions on Instrumentation and Measurement. 2009 May;58(5):1462-70.

[13] Farach JE, Grady WM, Arapostathis A. An optimal procedure for placing sensors and estimating the locations of harmonic sources in power systems. IEEE Transactions on Power Delivery. 1993 Jul;8(3):1303-10.

[14] Srinivasan D, Ng WS, Liew AC. Neural-network-based signature recognition for harmonic source identification. IEEE Transactions on Power Delivery. 2006 Jan;21(1):398-405.

[15] Hamzah N, Mohamed AZ, Hussain A. Identification of harmonic source at the point of common coupling based on voltage indices. J. Teknol. 2005 Dec;43(1):11-32. 
[16] Yusoff MR, Sutikno T, Habban MF. An Improved Detection and Classification Technique of Harmonic Signals in Power Distribution by Utilizing Spectrogram. International Journal of Electrical and Computer Engineering (IJECE). 2017 Feb 1;7(1):12-20.

[17] Victor LR, Jidin A, Karim KA, Sutikno T, Sundram R, Jopri MH. Improved Torque Control Performance of Direct Torque Control for 5-Phase Induction Machine. International Journal of Power Electronics and Drive Systems. 2013 Dec 1;3(4):391.

[18] Ahmadi MZ, Jidin A, binti Jaffar K, Othman MN, Nagarajan RN, Jopri MH. Minimization of torque ripple utilizing by 3-L CHMI in DTC. InPower Engineering and Optimization Conference (PEOCO), 2013 IEEE 7th International 2013 Jun 3 (pp. 636-640). IEEE.

[19] Vaid K, Sood YR, Jarial RK. Identification of harmonic sources in deregulated power sector. Int. J. Eng. Sci. Technol. 2011;3(3):2435-42.

[20] Yusoff MR, Sutikno T, Habban MF. An Improved of Multiple Harmonic Sources Identification in Distribution System with Inverter Loads by Using Spectrogram. International Journal of Power Electronics and Drive Systems. 2016 Dec 1;7(4).

[21] Papic I. Harmonic contributions evaluation with the harmonic current vector method. IEEE Transactions on Power Delivery. 2008 Jan;23(1):425-33.

[22] Blazic B, Pfajfar T. A modified harmonic current vector method for harmonic contribution determination. InPower Systems Conference and Exposition, 2004. IEEE PES 2004 Oct 10 (pp. 1470-1475). IEEE.

[23] Balci ME, Hocaoglu MH. On the validity of harmonic source detection methods and indices. InHarmonics and Quality of Power (ICHQP), 2010 14th International Conference on 2010 Sep 26 (pp. 1-5). IEEE.

[24] D'Antona G, Muscas C, Pegoraro PA, Sulis S. Harmonic source estimation in distribution systems. IEEE Transactions on Instrumentation and Measurement. 2011 Oct;60(10):3351-9.

[25] Martin KE, Benmouyal G, Adamiak MG, Begovic M, Burnett RO, Carr KR, Cobb A, Kusters JA, Horowitz SH, Jensen GR, Michel GL. IEEE standard for synchrophasors for power systems. IEEE Transactions on Power Delivery. 1998 Jan;13(1):73-7.

[26] Kassim NM, Manap M, Ngatiman NA, Yusoff MR. Localization of Multiple Harmonic Sources for Inverter Loads Utilizing Periodogram. Journal of Telecommunication, Electronic and Computer Engineering (JTEC). 2016 May $1 ; 8(2): 87-91$

[27] D. Committee, I. Power, and E. Society, IEEE Recommended Practice and Requirements for Harmonic Control in Electric Power Systems IEEE Power and Energy Society, IEEE Std 519 ${ }^{\mathrm{TM}}-2014$ vol. 2014, 2014.

[28] Habban MF, Sutikno T. An Accurate Classification Method of Harmonic Signals in Power Distribution System by Utilising S-Transform. Telkomnika. 2017 Mar 1;15(1).

[29] Abdullah AR, Abidullah NA, Shamsudin NH, Ahmad NH. Performance Verification of Power Quality Signals Classification System. In Applied Mechanics and Materials 2015 (Vol. 752, pp. 1158-1163). Trans Tech Publications.

[30] Abdullah AR, Abidullah NA, Shamsudin NH, Ahmad NH. Power Quality Signals Classification System Using Time-Frequency Distribution. In Applied Mechanics and Materials 2014 (Vol. 494, pp. 1889-1894). Trans Tech Publications.

[31] Abidullah NA, Abdullah AR, Sha'ameri AZ, Shamsudin NH, Ahmad NH. Real-Time Power Quality Disturbances Detection and Classification System. World Applied Sciences Journal. 2014;32(8):1637-51.

[32] Abidullah NA, Peng GZ, Abdullah AR. A new two points method for identify dominant harmonic disturbance using frequency and phase spectrogram. Int. Rev. Electr. Eng. 2014;9(2):453-9 